\title{
Agregação de pontos de vista de stakeholders utilizando o Value-Focused Thinking associado à mapeamento cognitivo
}

\author{
Simone de Almeida ${ }^{\mathrm{a}}$, Danielle Costa Morais ${ }^{\mathrm{b} *}$, Adiel Teixeira de Almeida \\ asimonea@utfpr.edu.br, UTFPR, Brasil \\ b*daniellemorais@yahoo.com.br, UFPE, Brasil \\ calmeidaatd@gmail.com, UFPE, Brasil
}

\begin{abstract}
Resumo
Este artigo propõe uma nova abordagem para agregação das opiniões de diferentes stakeholders baseado na utilização do Value-Focused Thinking associada ao mapeamento cognitivo. Esta abordagem proposta foi aplicada para a determinação do preço de venda, concentrando-se no caso particular de uma farmácia de manipulação da região Sul do Brasil, o que propiciou um melhor entendimento do problema pelos envolvidos. Este artigo também identifica as implicações de se trabalhar com um grupo de stakeholders isoladamente, gerando diferentes modelos e agregando os pontos de vista a fim de gerar um único resultado no processo de precificação dos insumos.
\end{abstract}

Palavras-chave

Formação do preço de venda. Tomada de decisão. Value-Focused Thinking. Mapas cognitivos.

\section{Introdução}

Decisões são atividades constantes do dia a dia das pessoas em geral, e são particularmente importantes no contexto da realidade das empresas. No cenário atual de contínua mudança, faz-se necessário alerta permanente por parte dos gestores, para percepção do que os ambientes interno e externo à organização indicam em relação às ameaças e oportunidades, para que as escolhas sejam feitas com base na realidade da empresa, considerando seus valores.

Uma decisão precisa ser tomada sempre que se está diante de um problema que possui mais de uma alternativa para sua solução. Sendo problema qualquer assunto ou questão que envolve dúvida, incerteza ou dificuldade. Decidir é recomendar entre vários caminhos alternativos que levam a determinado resultado. $\mathrm{Ou}$, ainda, decidir é posicionar-se em relação ao futuro (GOMES; GOMES; ALMEIDA, 2009).

Para Almeida (2011, p. 15), “[...] o processo decisório pode envolver apenas um decisor ou um grupo de decisores". 0 autor salienta ainda que mesmo decisões individuais podem sofrer influência de diversos outros atores no processo decisório. Embora esses atores não exerçam diretamente o poder sobre a decisão, de alguma maneira podem influenciar no processo. Nas decisões individuais prevalecem os valores do decisor e, nas coletivas, o importante é o posicionamento e a maturidade do grupo.

Tendo em vista a complexidade do ambiente que envolve as empresas atualmente, é crescente a quantidade de modelos na literatura que tratam sobre tomada de decisão em grupo em problemas complexos (MORAIS; ALMEIDA, 2010, 2012). Apesar disso, de acordo com Alencar, Morais e Almeida (2010), ainda há muitos problemas de decisão em grupo que são modelados como se uma única pessoa fosse a responsável por essa decisão, embora isso não represente a situação real.

No entanto, os métodos desenvolvidos na área da Teoria da Decisão possibilitam a elaboração de modelos que oferecem técnicas para a estruturação do problema e funções que permitem representar os julgamentos e as preferências dos decisores de forma consistente durante o processo de tomada de decisão. Muitas abordagens surgiram com objetivo 
de estruturar um determinado problema antes da tomada de decisão, algumas dessas abordagens são apresentadas a seguir.

Warfield (1994) descreve Delphi como um método de geração, esclarecimento, estruturação e contribuição de ideias. É utilizado para coletar e avaliar informações ou opiniões dos especialistas a respeito de um tema. É um método em que os grupos não podem ou não devem manter uma comunicação face a face. E, como regra, é um método lento, mas que pode ser acelerado pelo uso de meios de comunicação ou computadores (BOSE; DAVEY; OLSON, 1997).

0 método Strategic Options Development and Analysis (SODA) caracteriza-se por sua capacidade de lidar com fatores qualitativos, de estruturar situações difíceis e no desenvolvimento de estratégias (EDEN; ACKERMANN, 2004). SODA é uma técnica de estruturação orientada para a visão global e a resolução de problemas complexos por parte de um grupo pequeno. As ferramentas básicas para a abordagem são os mapas cognitivos e o COPE - Cognitive Policy Evaluation (software interativo de apoio à decisão em grupo com representação gráfica para análises qualitativas). A estrutura geral dos mapas cognitivos envolve três conceitos: os que identificam os objetivos do mapa; os que assumem o papel de ideias-chave que direcionam o raciocínio do decisor e os que indicam as ações que podem ser tomadas.

0 método Strategic Choice Approach (SCA) é uma estratégia cujo principal objetivo é proporcionar o gerenciamento de riscos e incertezas. Facilitadores guiam os participantes a analisarem a relação entre as diferentes áreas envolvidas. Comparações interativas entre as alternativas, utilizando esquemas, facilitam a definição das incertezas. A aplicação do SCA é dividida em quatro fases ou modos: Shaping, Designing, Comparing e Choosing (FRIEND, 2004).

Soft Systems Methodology (SSM) é uma metodologia desenvolvida por Checkland que trabalha com o ambiente e o aprendizado para analisar problemas complexos envolvendo um grupo (CHECKLAND, 2004). Procura descobrir os aspectos cruciais de uma situação problema, fazendo com que as pessoas reflitam sobre como esse problema surgiu ou quais são seus processos fomentadores (WINTER, 2006). A discussão entre os stakeholders busca o equilíbrio de compromisso entre o ideal e o factível, procurando obter embasamento e adeptos para a implementação das soluções.

A SSM foi projetada para ajudar a formular e resolver situações chamadas soft, problemas desestruturados e complexos e geralmente com vários componentes humanos, apresentando, em função dessa característica, diferentes percepções do mesmo problema ou objetivo, diferentes Weltanschauungen (visões do mundo) dos diversos stakeholders envolvidos no sistema. Os participantes do processo constroem um modelo conceitual ideal para cada ponto de vista. Os modelos são comparados com o modelo existente até chegar a um único, factível e desejável modelo (CHECKLAND, 2004).

É importante ressaltar que, além dos métodos descritos acima, existem inúmeros outros, os quais tradicionalmente enfrentam os problemas de decisão identificando alternativas - a partir delas consideram-se os objetivos ou os critérios de avaliação. Esse ponto de vista foi rotulado por Keeney (1992) como Alternative Focused Thinking - AFT, ou seja, uma forma reativa de tratar um problema de decisão. Segundo o autor, o que dirige um processo de decisão são os valores que representam os princípios para avaliação da desejabilidade de qualquer alternativa possível ou consequência.

Keeney (1992) definiu como Value-Focused Thinking - VFT o processo pelo qual se busca a identificação dos valores que o decisor deverá utilizar como norteador do processo geral de decisão. A abordagem Value-Focused Thinking é um caminho para identificar situações desejáveis de decisão e então coletar os benefícios dessas situações para resolvê-las, ou seja, essencialmente, ela consiste de duas atividades: decidir o que você deseja e então descobrir como alcançá-lo. Fornece uma forma estruturada de pensar sobre as decisões, de desenvolver e de apoiar julgamentos subjetivos que são fundamentais para decisões eficientes.

Alguns benefícios da utilização da abordagem VFT, são a geração de melhores alternativas para qualquer problema decisório e a transformação dos problemas de decisão em oportunidades de decisão. Pensar sobre os valores auxilia na criação de alternativas, revela objetivos não conhecidos, gera oportunidades de decisão, evita que se tomem decisões desconectadas dentro da organização, facilita as decisões por parte dos stakeholders e melhora a comunicação, dentre outros benefícios (ALENCAR; MOTA; ALENCAR, 2011).

A obtenção dos valores é essencial para guiar o processo de tomada de decisão. 0 processo de explicitação de valores inicia com o processo de identificação de objetivos, que deve acontecer por meio de entrevistas com os tomadores de decisão e stakeholders (KEENEY, 1992, 1996; BOSE; DAVEY; OLSON, 1997).

Após pesquisa realizada nos diversos métodos de estruturação de problema propostos pela literatura, identificou-se que todos apresentam detalhes de sua utilização com apenas um decisor e que quando há a participação de um grupo de decisores os métodos 
estão associados ao processo de negociação. Dessa forma, a fim de contribuir para a resolução de problemas em grupo, este artigo propõe uma nova abordagem para agregação das opiniões de diferentes stakeholders em um processo decisório.

Visto tratar-se de um processo decisório em grupo que é de natureza subjetiva, é importante o uso de métodos que possam tratar essa subjetividade de uma maneira formal e estruturada. A ideia não é reduzir a subjetividade do problema. Pelo contrário, o que se pretende é incorporar esta subjetividade no modelo de decisão (ALMEIDA, 2011). Vale destacar que os atores envolvidos no processo devem incluir os seus valores pessoais, o que confirma o fato de o problema abordado ser de natureza subjetiva.

Considerando os benefícios do método VFT, decidiu-se utilizá-lo na abordagem proposta neste trabalho. Para auxiliá-lo na fase inicial de identificação dos valores dos decisores foi utilizado o mapeamento cognitivo do método SODA com o objetivo de retratar ideias, sentimentos, valores e atitudes e seus interrelacionamentos, de forma a tornar possível um estudo e uma análise posterior, utilizando para tal uma representação gráfica.

Essa representação gráfica será o resultado da representação mental que o facilitador fará a partir da discussão feita pelo ator sobre o problema, aproveitando assim os benefícios de uma decisão individual para gerar uma visão do grupo do processo de tomada de decisão.

Além da combinação do VFT e SODA, o trabalho propõe a participação de diferentes stakeholders no processo de estruturação do problema e apresenta uma forma de agregação dos diferentes modelos individuais, gerando um resultado único. Essa abordagem proposta foi aplicada para a determinação do preço de venda, concentrando-se no caso particular de uma farmácia de manipulação da região Sul do Brasil.

Nesse contexto, a relevância da abordagem proposta neste trabalho, reside basicamente em apoiar os atores envolvidos na determinação do preço de venda, para uma tomada de decisão estruturada de forma a integrar as diferentes preferências de todos os stakeholders, considerando seus pontos de vista, interesses específicos e as diferentes percepções da situação problema e obtendo um modelo unificado.

\section{Abordagem proposta}

A abordagem proposta se utiliza da combinação dos métodos VFT e SODA, com o objetivo de extrair os pontos fortes de cada um e assegurar uma estrutura de valores mais enriquecida, por agregar diferentes percepções da situação problema. Essa abordagem envolve diferentes stakeholders de forma isolada e pressupõe que cada stakeholder pertence à mesma empresa, podendo possuir os mesmos objetivos, apesar da diferença entre as percepções individuais, objetivos, preferências e interesses, funções exercidas e responsabilidades assumidas.

0 processo de implantação da abordagem proposta é representado através de um fluxograma, o qual é apresentado na Figura 1. Esse é composto por cinco etapas, das quais somente a última poderá se submeter a um processo de negociação, caso a solução obtida seja rejeitada pelos stakeholders. Segundo Alencar e Almeida (2010a, b), um dos problemas da decisão em grupo diz respeito à concordância entre os decisores quanto aos parâmetros do modelo, tais como alternativas, critérios e pesos, por exemplo, os quais devem representar um consenso do grupo, seja unânime ou, pelo menos, da grande maioria, o que nem sempre é possível.

Todas as etapas da abordagem prevêem a presença de todos os stakeholders isoladamente para definição do objetivo fundamental com o objetivo de estabelecer a meta a ser alcançada pelos atores. Para melhor estruturar essa etapa é utilizado o método SODA (Strategic Options Development and Analysis), cuja função será identificar o problema geral e seus objetivos e que usa mapas cognitivos como dispositivos de modelagem para elicitar e armazenar os pontos de vista dos decisores sobre a situação problema. Todas as atividades relativas à elaboração dos mapas cognitivos são acompanhadas por um facilitador.

Os mapas cognitivos individuais são agregados, buscando estabelecer clusters quando os pontos de vista forem convergentes. Para os pontos de vista divergentes, o processo será apenas uni-los, gerando um único mapa, de maneira que ele represente a visão de todos os participantes. Após o encerramento dessa atividade, as etapas seguintes continuam sendo realizadas de maneira totalmente individualizada, portanto, gerando diversos modelos distintos.

Quando há incerteza nos problemas de decisão, é possível associar a cada alternativa diferentes consequências e suas probabilidades, inserindo no modelo uma etapa de modelagem probabilística, em complemento à modelagem de preferências do decisor. Nesse caso, as alternativas são avaliadas pela utilidade esperada. A forma da função utilidade depende das condições de independência dos critérios. Essas condições são: independência em utilidade e independência aditiva.

Para Almeida (2011) um atributo (ou critério) $Y$, em que $Y$ está contido em um conjunto $X$, é independente em utilidade de seu complemento, se a ordem de preferência para loterias envolvendo 


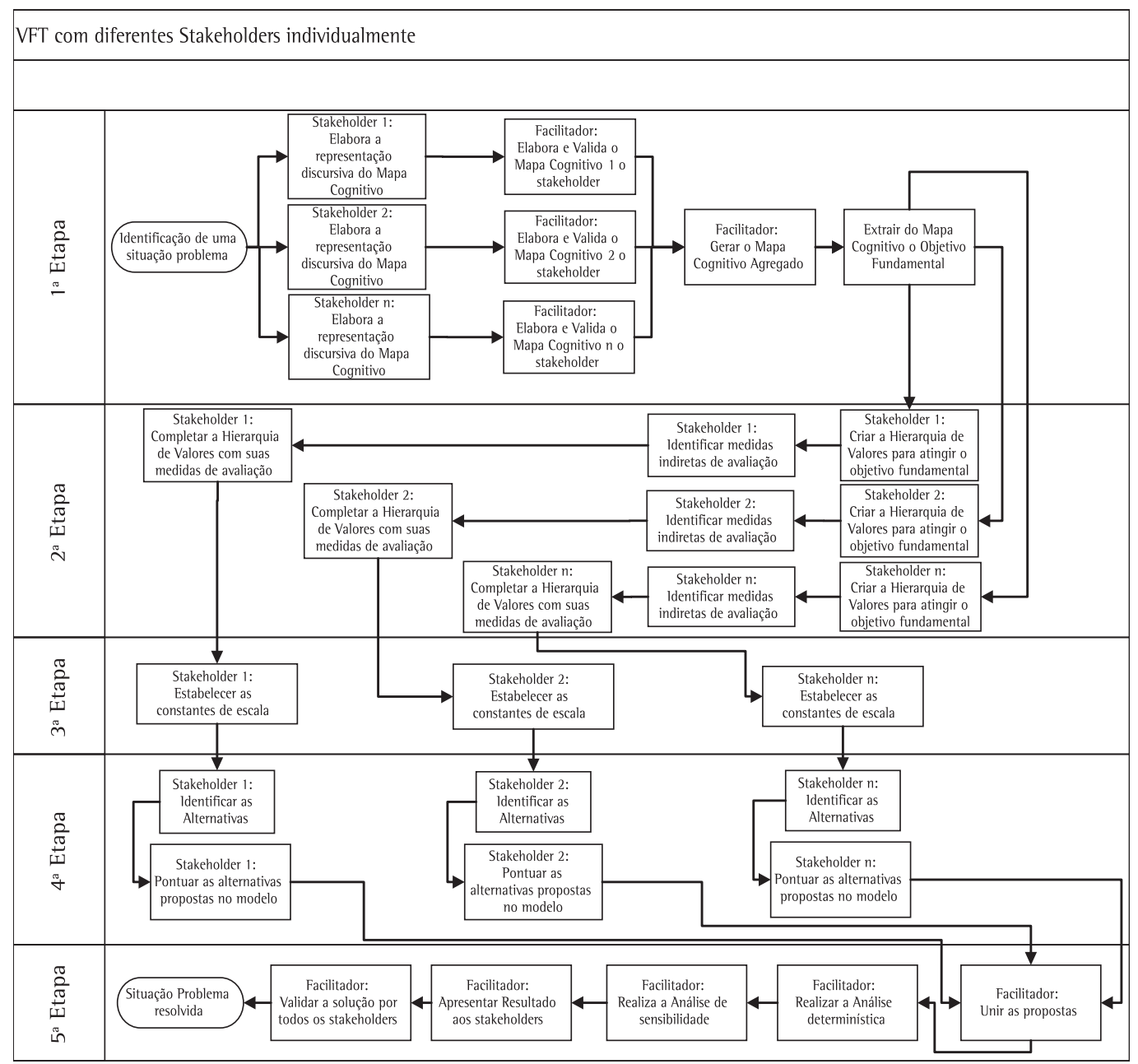

Figura 1. Visão macro da aplicação VFT por diferentes stakeholders individualmente.

apenas mudanças no nível de $Y$ não depender do nível no qual os atributos $Y$ são fixados.

Os atributos $X=\left\{X_{1}, X_{2}, X_{3}, \ldots, X n\right\}$ são independentes aditivamente se as preferências sobre loterias dependem apenas das probabilidades marginais dos atributos $\mathrm{X} 1, \mathrm{X} 2, \mathrm{X} 3, \ldots, \mathrm{Xn}$ mas não da probabilidade conjunta desses atributos.

Quando houver a independência aditiva entre dois atributos, a função utilidade pode adquirir a forma de uma função aditiva. Ela permite adicionar as contribuições dos dois atributos, encontrando mais facilmente a utilidade total u (y, z). Nesse caso, a condição de independência aditiva não permite que haja nenhuma interação entre os critérios (GOMES; GOMES; ALMEIDA, 2009).

Verificada a condição de independência aditiva, o processo de avaliação das alternativas ocorrerá pela pontuação do modelo de valor, o qual faz uso da função valor aditiva para calcular a pontuação final de cada alternativa. Assim, cada alternativa teria valores diferenciados de acordo com a visão de cada decisor. Em seguida, o resultado será somado, chegando-se dessa forma a um ranking. Usando um modelo de função valor aditiva, é introduzida a importância dos critérios sob a forma de constantes de escala, a qual define os trade-offs entre as alternativas.

Com o ranking estabelecido, a alternativa de maior pontuação será a melhor solução encontrada por todos os stakeholders. A aplicação da abordagem proposta é apresentada em detalhes a seguir, como também é feita a delimitação do contexto do problema a ser estruturado, por meio da realização de um estudo de caso prático para definição do preço de venda das fórmulas magistrais preparadas por uma farmácia de manipulação, utilizada na obtenção de dados reais. 


\subsection{Domínio do problema}

As empresas vêm enfrentando constantes desafios para sobreviverem e/ou para crescerem no mercado atual, o que as leva a concentrarem seus esforços no desenvolvimento de estratégias que visam a competitividade.

Segundo Sartori (2004), o preço é o principal elemento que alavanca a competitividade e, consequentemente, a rentabilidade de uma empresa. De acordo com Dutra e Hatakeyama (2005), o preço de venda vem se transformando num importante fator de competição, e de sua correta formação depende o sucesso de uma empresa, principalmente em estruturas de mercado altamente competitivas. Para os autores, o preço de venda é um fator determinante para o sucesso de um negócio, podendo-se encontrar muitos estudos que buscam identificar as melhores estratégias para a sua obtenção.

De acordo com a ANVISA (AGÊNCIA..., 2000), o regulamento técnico que institui as Boas Práticas de Manipulação em Farmácias, define farmácia de manipulação como estabelecimento de manipulação de fórmulas magistrais e oficinais, de comércio de drogas, medicamentos, insumos farmacêuticos e correlatos, compreendendo o de dispensação e o de atendimento privativo de unidade hospitalar ou de qualquer outra equivalente de assistência médica, além de fracionar produtos industrializados.

Como fórmulas magistrais entende-se o processo de preparação do medicamento na farmácia atendendo prescrições médicas, profissional que estabelece sua composição, forma farmacêutica, posologia e modo de usar. E fórmula oficinal é aquela preparada na farmácia atendendo a uma prescrição cuja fórmula está inscrita na farmacopéia brasileira ou em compêndios ou formulários reconhecidos pelo Ministério da Saúde.

Como em muitas empresas, segundo dados divulgados pela ANFARMAG (ASSOCIAÇÃO..., 2011), o ramo específico das farmácias de manipulação vem aumentando sua participação no mercado, acarretando grande concorrência, além de disputar o mercado com as grandes indústrias de produção de medicamentos. Dessa forma, elas precisam aumentar sua competitividade e o preço, como já afirmado por alguns autores, é fator determinante para se alcançar esse objetivo.

\subsection{Agregação dos mapas cognitivos}

Para a realização do estudo foram feitas entrevistas com dois stakeholders de uma farmácia de manipulação (proprietária da farmácia e responsável técnica), com foco na identificação dos objetivos e valores que permeiam as decisões que envolvem a precificação de seus produtos.

Para a identificação dos valores dos stakeholders foram utilizadas diversas técnicas propostas por Keeney (1992), tais como: lista de desejos, alternativas ótimas, médias e péssimas, problemas e fraquezas da organização, consequências, objetivos estratégicos e objetivos genéricos. A utilização dessas técnicas propiciou a obtenção dos valores e conceitos, que foram confirmados posteriormente pelo facilitador pela constatação da redundância, isto é, os mesmos valores do stakeholder foram revelados com o emprego de diferentes técnicas.

Os valores e conceitos foram separados em objetivos estratégicos e objetivos-meio, utilizando as perguntas clássicas do método VFT. Na direção dos objetivos fundamentais, a pergunta utilizada foi: "Por que aquilo é importante?", e, no sentido inverso: "Como você pode alcançá-lo?" Finalmente, o método prevê a construção da hierarquia de valores entre os objetivos fundamentais e das ligações entre os objetivos-meio. Paralelamente foi construído o mapa cognitivo, a partir dos elementos primários de avaliação - EPA, que nesse caso foram obtidos pelo método VFT.

As entrevistas foram realizadas por um facilitador, utilizando-se para tanto dos conceitos do VFT propostos por Keeney (1996) e dos conceitos gerais para elaboração do mapa cognitivo conforme descritos por Eden e Ackermann (2004). Paralelamente à realização das entrevistas foram construídos os mapas cognitivos, representando os pontos de vista de cada ator. A Figura 2 mostra a visão da proprietária da farmácia (stakeholder 1) e a Figura 3 mostra o ponto de vista da responsável técnica (stakeholder 2).

De acordo com a Figura 2, a proprietária da farmácia valoriza, além de custos, mercado, concorrência, fornecedor, receita, marketing; o consumidor, despesas, parcerias com outros profissionais da saúde e o estoque.

Por outro lado, a responsável técnica diferenciou-se da proprietária quando identificou a margem de lucro como aspecto relevante para o atendimento do objetivo fundamental, ou seja, tornar-se mais competitivo, e omitiu consumidor, despesas, estoque e parceiros. A responsável técnica valoriza também custos, mercado, concorrência, fornecedor, receita e marketing, além da margem de lucro, conforme apresentado na Figura 3.

Cabe enfatizar que as entrevistas foram realizadas isoladamente e que nenhum stakeholder teve conhecimento prévio das preferências do outros participantes. É possível perceber ainda que o objetivo estratégico identificado é muito similar: ser competitivo é o que se espera com um preço mais competitivo em relação ao mercado e concorrentes. 


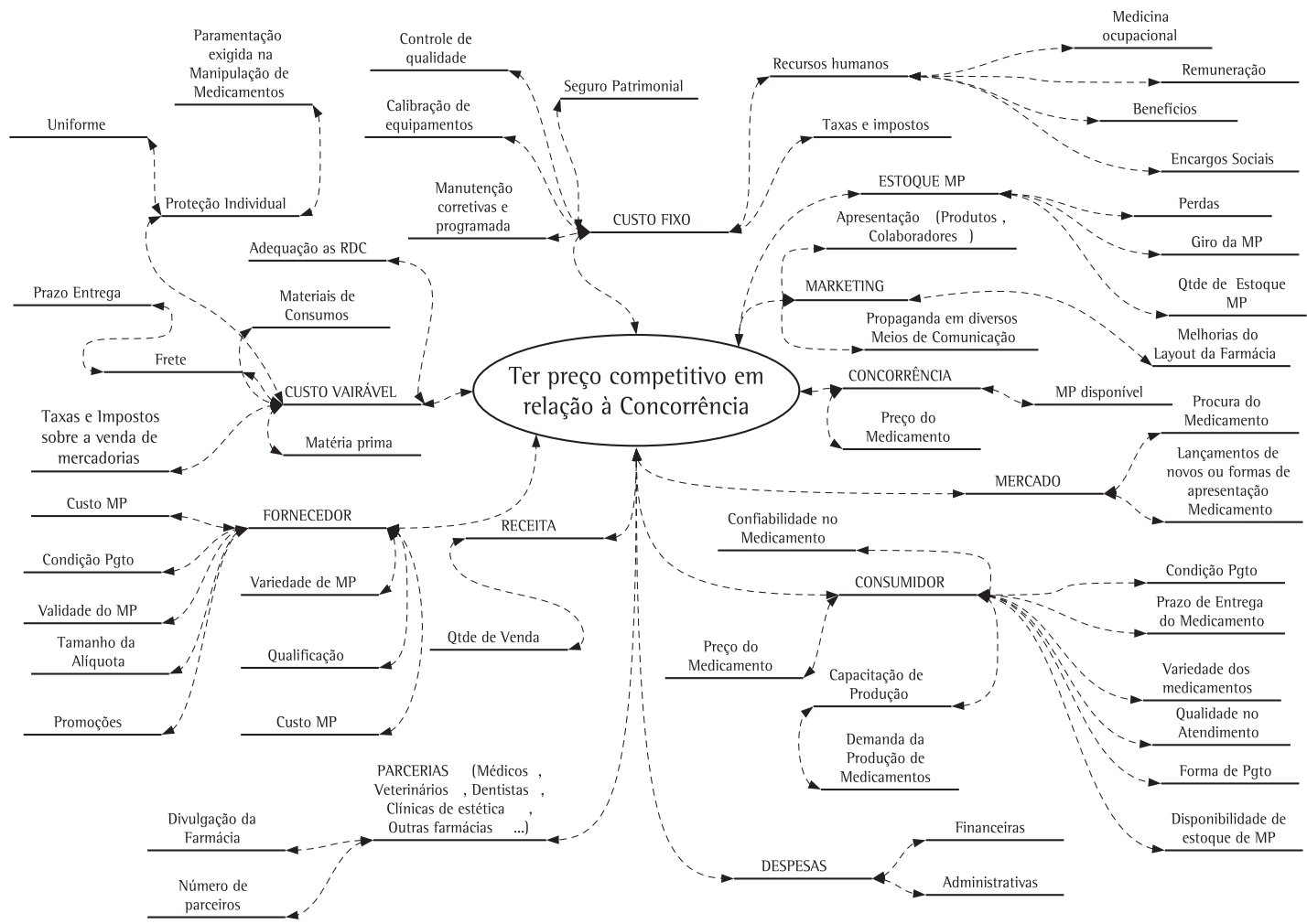

Figura 2. Mapa cognitivo da proprietária.

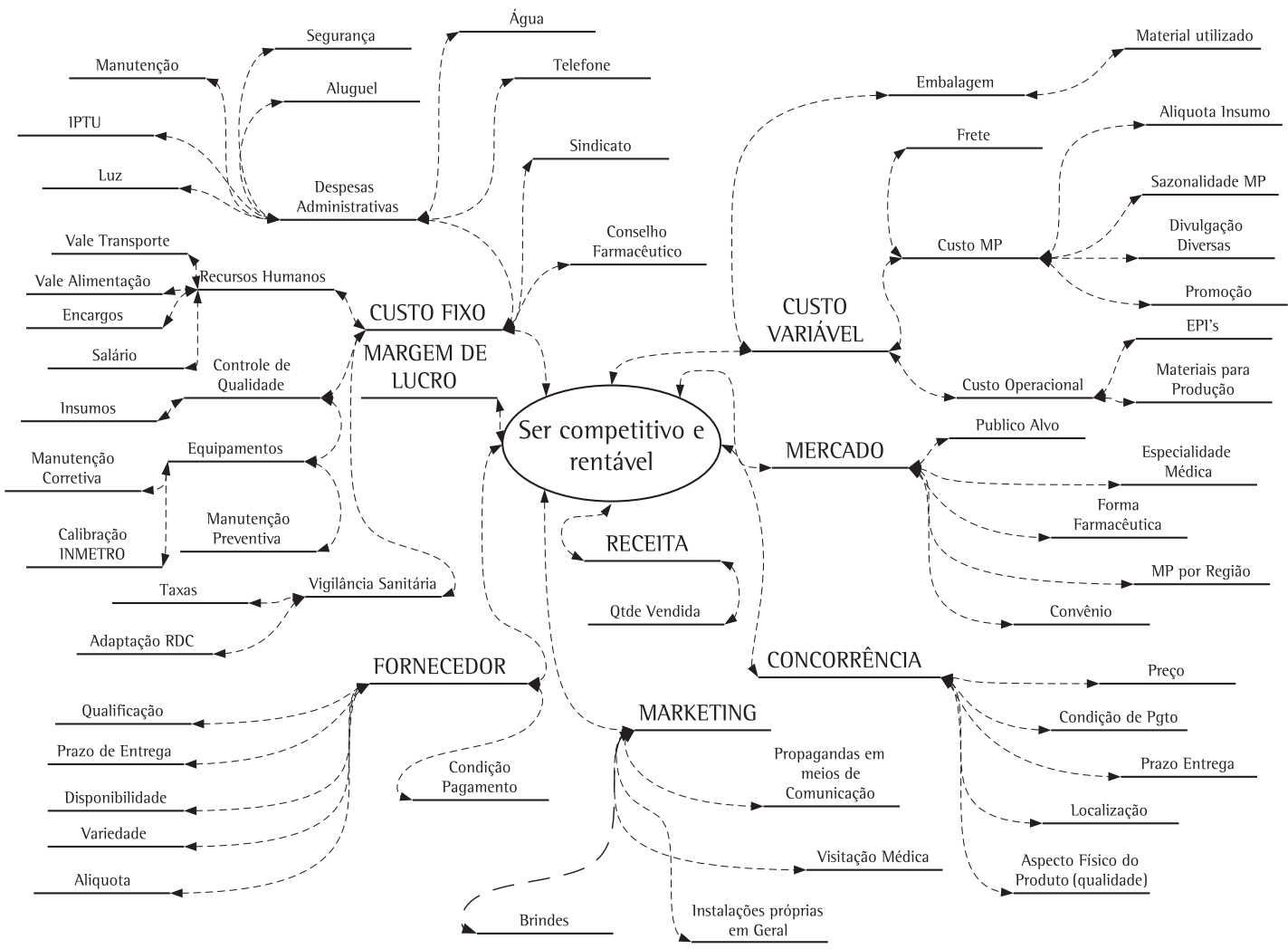

Figura 3. Mapa cognitivo da responsável técnica. 
Após o encerramento de todas as etapas previstas para aplicação do método VFT, alguns modelos foram criados, de acordo com a visão e interesse que cada stakeholder tem do processo de precificação de produtos. Porém é necessário estabelecer um mecanismo que possibilite unir todos os pontos de vista e criar um modelo unificado que atenda a todos os stakeholders.

Diante disso, a partir da aplicação da operação de união entre os conjuntos de valores dos stakeholders, foi gerado o mapa cognitivo agregado apresentado na Figura 4. Cabe salientar que foram extraídos os verbos das frases para simplificar a visualização dos mapas.

0 processo iniciou-se com a criação dos conjuntos e subconjuntos dos valores identificados nos mapas elaborados pela proprietária e pela responsável técnica, que aqui serão chamados de conjunto de valores de $P$ e de $R$, respectivamente.

0 processo foi realizado a partir da definição do objetivo estratégico que, de acordo com as stakeholders é ser competitivo e rentável em relação à concorrência. Em seguida criou-se um subconjunto dos conceitos de nível 1 dos conjuntos P e R, ou seja, os objetivos fundamentais destacados em negrito e escritos em letra maiúscula, conforme ilustrado na Figura 4. A operação de união juntou as definições da seguinte forma: receita, custo fixo, custo variável, fornecedor, marketing, concorrência e mercado apareceram em ambos os conjuntos, portanto uniram-se os elementos em um único conjunto chamado agora de $\mathrm{G}$ (geral).

No conjunto $P$, os seguintes elementos distintos de R: consumidor, parcerias, despesas, e estoque foram acrescidos ao conjunto G. Da mesma forma, no conjunto $\mathrm{R}$ existia um elemento que o distinguia de $\mathrm{P}$, margem de lucro, que também foi incluído no conjunto G.

Para os demais níveis, o processo ocorreu da mesma forma, gerando finalmente o mapa apresentado na Figura 4. Os elementos em negrito e itálico são os que eram divergentes entre os conjuntos $\mathrm{P}$ e R, os quais foram adicionados no conjunto $\mathrm{G}$, criando o modelo final do processo.

Depois de realizada a união dos mapas cognitivos foi possivel extrair os valores dos decisores e elaborar a hierarquia de valores, dando continuidade ao processo de estruturação do problema.

Percebe-se o grande volume de objetivos-meio identificados com a utilização do mapeamento cognitivo de maneira individual, o que colabora com a estruturação do problema, pois diferentes percepções são tratadas de maneira isolada para posterior agregação, completando a visão do problema.

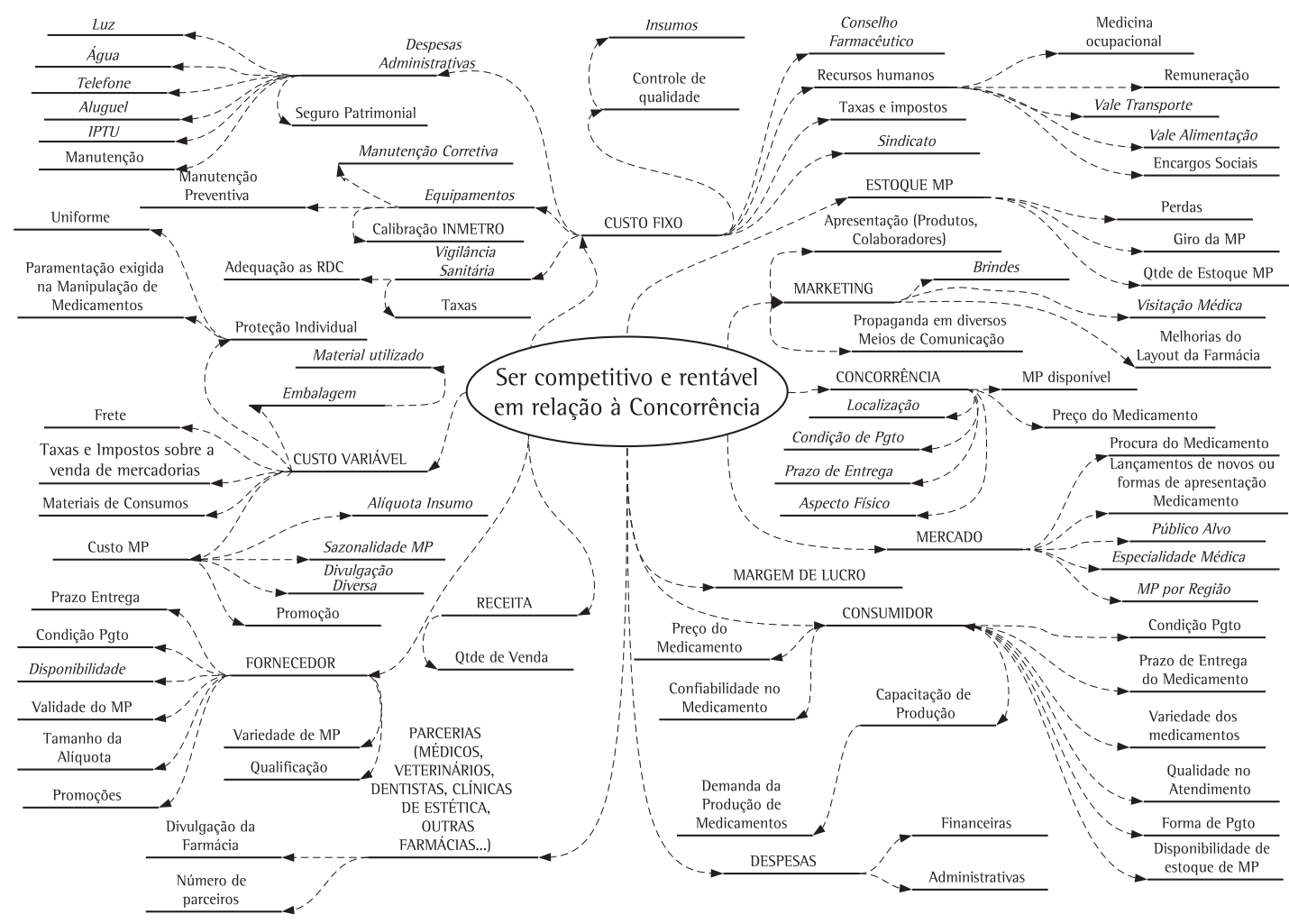

Figura 4. Mapa cognitivo agregado. 


\subsection{Medidas de avaliação}

Existem três tipos de atributos (KEENEY, 1992): natural, construído direto e construído indireto, também chamado de proxy. Para cada atributo deve ser estabelecida uma medida de avaliação, a qual prevê a escala "[...] para o grau de realização de um objetivo [...]” (KIRKWOOD, 1997, p. 24), também conhecida como a medida de eficácia ou medida do desempenho de um objetivo.

Essas medidas se prestam à avaliação dos objetivos associados, como, por exemplo: se o objetivo fosse minimizar o custo, o atributo "custo medido em reais" é um atributo natural (KEENEY, 1992). Os atributos naturais usam medidas comumente interpretadas por todos, como a utilização de quilometragem para medir a distância. Em muitos casos é necessário o uso de uma medida construída, por não existirem medidas naturais para muitos objetivos. Diferentemente dos atributos naturais, que são utilizados em vários contextos, os atributos construídos são desenvolvidos para um contexto de decisão específico (KEENEY, 1992).

Exemplos de objetivos sem atributo natural incluem "melhorar a imagem da corporação" em um contexto de negócios, "minimizar a desfiguração facial" em um contexto médico, e "aumentar o prestígio internacional do país" em um contexto governamental (KEENEY, 1992, p. 101). Esses objetivos envolvem um conjunto de aspectos que podem não ter meios de medição claros e universalmente aceitos. Em casos como esses, as medidas construídas não só permitem a avaliação dos objetivos mas também ajudam a definir o que se quer dizer com o objetivo. Esses atributos podem ter uma medida de avaliação descrita em diferentes níveis em uma escala verbal, por exemplo.

No entanto, existem casos em que é difícil identificar atributos naturais ou mesmo construir atributos de forma direta. Para esses casos usam-se os atributos proxy, ou construídos indiretos. Por exemplo, o objetivo é minimizar os danos da chuva ácida a estátuas de pedra, então como identificar um atributo natural ou construído direto para medir a deformação das estátuas de pedra? Nesse caso, um atributo proxy definido como a medida de concentração de dióxido de enxofre em partes por milhão pode ser adequado (KEENEY, 1992).

Depois da realização das entrevistas com os stakeholders para a identificação das medidas dos seus valores, essas foram unidas conforme apresentado na Tabela 1.

Na Tabela 1 verifica-se que, além dos atributos naturais, há vários atributos construídos diretos, não sendo identificado nenhum atributo proxy. Para cada atributo deve ser estabelecida uma escala de avaliação, que pode ser numérica ou verbal. Entre as escalas numéricas, pode haver vários tipos de escalas, tais como: de razão, intervalar, de diferenças e ordinal (ALMEIDA, 2011). Os atributos naturais são avaliados por uma escala de intervalo.

As Tabelas 2, 3 e 4 são utilizadas para avaliar, respectivamente, a demanda por medicamentos, a confiabilidade dos medicamentos da farmácia e a variedade de medicamentos, como forma de exemplificar as escalas criadas pelos stakeholders para medir os atributos construídos diretos. A identificação das categorias listadas nas Tabelas 2, 3 e 4, são representações particulares da percepção dos atores em relação ao problema em análise. Destaca-se que o procedimento de criação das tabelas de categorias foi realizado para todos os atributos construídos diretos.

\subsection{Avaliação das alternativas}

De acordo com o conhecimento de mercado e orientadas pelo facilitador foram estabelecidas quatro alternativas existentes atualmente no mercado, ou seja, a precificação baseada simplesmente nos custos fixos e variáveis da farmácia (BC). Dessa forma, o preço deveria cobrir todos os custos e despesas realizados pela empresa. Outra alternativa identificada foi a baseada no mercado (BME), assim quem ditaria as regras de precificação dos insumos seria apenas o mercado. Outra forma analisada é a baseada na concorrência (BCR), ou seja, somente o preço praticado pela concorrência seria base para o estabelecimento do preço da farmácia. E, finalmente, a última alternativa seria a baseada no mark-up (BMU).

Entende-se por mark-up o processo que se utiliza de um índice (multiplicador ou divisor) aplicado sobre o custo do produto, mercadoria ou serviço para se determinar o preço de venda. Esse índice é denominado mark-up. Santos (2005, p. 190) define mark-up como "[...] um índice aplicado sobre o custo de um bem ou serviço para formação do preço de venda”. Os componentes do mark-up são determinados através de relações percentuais sobre o preço de venda e, em seguida, aplicados sobre o custo dos produtos; todavia constatam-se algumas diferenças, entre os estudiosos da área, em torno dos itens de formação ou constituição do mark-up, mas que, em linhas gerais, são:

- Custos fixos de produção (quando se utilizar o método de custeio variável);

- Impostos sobre vendas (ICMS, PIS e Cofins);

- Despesas comerciais (fixas e variáveis);

- Despesas administrativas (fixas e variáveis);

- Despesas financeiras (capital de terceiros);

- Margem de lucro desejada. 
Tabela 1. Medidas de avaliação agregadas.

\begin{tabular}{|c|c|c|c|c|c|}
\hline Valor & $\begin{array}{l}\text { Unidade de medida } \\
\text { (mês) }\end{array}$ & $\begin{array}{l}\text { Tipo de } \\
\text { atributo }\end{array}$ & $\begin{array}{l}\text { Tipo de } \\
\text { medida }\end{array}$ & $\begin{array}{l}\text { Limite } \\
\text { inferior }\end{array}$ & $\begin{array}{l}\text { Limite } \\
\text { superior }\end{array}$ \\
\hline \multicolumn{6}{|l|}{ RECEITA } \\
\hline Quantidade de vendas & Reais & Natural & Quantidade & $15.000,00$ & Sem limite \\
\hline \multicolumn{6}{|l|}{ CUSTOS VARIÁVEIS } \\
\hline \multicolumn{6}{|l|}{ Matéria-prima } \\
\hline - Custo & Reais & Natural & Quantidade & $4.000,00$ & Sem limite \\
\hline - Alíquota & Grama & Natural & Quantidade & 1 & Sem limite \\
\hline - Sazonalidade & Unidade & Constr. direto & Categoria & 1 & 0 \\
\hline - Divulgações diversas & $\mathrm{N}^{0}$ de pessoas & Natural & Quantidade & 1 & Sem limite \\
\hline - Promoção & Reais & Natural & Quantidade & 0 & Sem limite \\
\hline \multicolumn{6}{|l|}{ Frete } \\
\hline - Valor do frete & Reais & Natural & Quantidade & 0 & Sem limite \\
\hline - Prazo de entrega & Dias & Natural & Quantidade & 1 & 7 \\
\hline \multicolumn{6}{|l|}{ Proteção individual } \\
\hline - Uniforme & Reais & Natural & Quantidade & 27,00 & 40,00 \\
\hline $\begin{array}{l}\text { - Paramentação exigida na manipulação de } \\
\text { medicamentos }\end{array}$ & Reais & Natural & Quantidade & 160,00 & 300,00 \\
\hline \multicolumn{6}{|l|}{ Custo operacional } \\
\hline - EPls & Reais & Natural & Quantidade & 0,10 & Sem limite \\
\hline - Materiais para produção & Reais & Natural & Quantidade & 0,05 & Sem limite \\
\hline Materiais de uso/consumo & Reais & Natural & Quantidade & 300,00 & 800,00 \\
\hline Taxas e impostos sobre a venda de mercadorias & Reais & Natural & Quantidade & $1.200,00$ & Sem limite \\
\hline Embalagem & Reais & Natural & Quantidade & 0,01 & 3,00 \\
\hline Adequação a RDC & Reais & Natural & Quantidade & 250,00 & Sem limite \\
\hline \multicolumn{6}{|l|}{ CUSTOS FIXOS } \\
\hline \multicolumn{6}{|l|}{ Despesas administrativas } \\
\hline - Aluguel & Reais & Natural & Quantidade & $1.600,00$ & $3.000,00$ \\
\hline - Manutenção & Reais & Natural & Quantidade & 0,00 & 200,00 \\
\hline - Seguro patrimonial (monitoramento e seguro) & Reais & Natural & Quantidade & 195,00 & 400,00 \\
\hline$-1 \mathrm{PTU}$ & Reais & Natural & Quantidade & 300,00 & 600,00 \\
\hline - Luz & Reais & Natural & Quantidade & 250,00 & 400,00 \\
\hline - Água & Reais & Natural & Quantidade & 15,00 & 40,00 \\
\hline - Telefone & Reais & Natural & Quantidade & 200,00 & 600,00 \\
\hline \multicolumn{6}{|l|}{ Vigilância sanitária } \\
\hline - Taxas & Reais & Natural & Quantidade & 60,00 & 100,00 \\
\hline - Adaptação RDC & Reais & Natural & Quantidade & 0,00 & Sem limite \\
\hline \multicolumn{6}{|l|}{ Recursos humanos } \\
\hline - Encargos & Percentual & Natural & Quantidade & $8 \%$ & $11 \%$ \\
\hline - Medicina ocupacional & Reais & Natural & Quantidade & 35,00 & 70,00 \\
\hline - Remuneração & Reais & Natural & Quantidade & $4.900,00$ & $9.900,00$ \\
\hline - Vale transporte (benefícios) & Reais & Natural & Quantidade & 570,00 & 700,00 \\
\hline - Vale alimentação & Reais & Natural & Quantidade & 800,00 & $1.000,00$ \\
\hline \multicolumn{6}{|l|}{ Controle de qualidade } \\
\hline - Insumos & Reais & Natural & Quantidade & 400,00 & 700,00 \\
\hline \multicolumn{6}{|l|}{ - Equipamentos } \\
\hline - Manutenção corretiva e programada (preventiva) & Reais & Natural & Quantidade & 210,00 & 500,00 \\
\hline - Calibração INMETRO & Reais & Natural & Quantidade & 30,00 & 100,00 \\
\hline Sindicato & Reais & Natural & Quantidade & 10,00 & Sem limite \\
\hline Conselho farmacêutico & Reais & Natural & Quantidade & 25,00 & Sem limite \\
\hline Taxas e impostos (ANVISA, FUBREBOM, coleta de lixo) & Reais & Natural & Quantidade & 50,00 & $2.500,00$ \\
\hline \multicolumn{6}{|l|}{ DEPESAS } \\
\hline Administrativas & Reais & Natural & Quantidade & 0 & Sem limite \\
\hline Financeiras & Reais & Natural & Quantidade & 0 & Sem limite \\
\hline \multicolumn{6}{|l|}{ MARGEM DE LUCRO } \\
\hline Margem de lucro & Percentual & Natural & Quantidade & 0 & Sem limite \\
\hline \multicolumn{6}{|l|}{ MERCADO } \\
\hline Demanda por medicamentos & Unidades & Constr. direto & Categoria & -2 & 2 \\
\hline $\begin{array}{l}\text { Lançamento de novos medicamentos ou } \\
\text { novas formas de apresentação }\end{array}$ & Unidades & Natural & Quantidade & 1 & Sem limite \\
\hline Público alvo & Unidades & Constr. direto & Categoria & 1 & 3 \\
\hline Especialidade médica & Unidades & Constr. direto & Categoria & 1 & 3 \\
\hline Forma farmacêutica & Unidades & Constr. direto & Categoria & 1 & 3 \\
\hline Matéria-prima por região & Unidades & Constr. direto & Categoria & 1 & 5 \\
\hline
\end{tabular}


Tabela 1. Continuação...

\begin{tabular}{|c|c|c|c|c|c|}
\hline Valor & $\begin{array}{l}\text { Unidade de medida } \\
\text { (mês) }\end{array}$ & $\begin{array}{l}\text { Tipo de } \\
\text { atributo }\end{array}$ & $\begin{array}{l}\text { Tipo de } \\
\text { medida }\end{array}$ & $\begin{array}{l}\text { Limite } \\
\text { inferior }\end{array}$ & $\begin{array}{l}\text { Limite } \\
\text { superior }\end{array}$ \\
\hline \multicolumn{6}{|l|}{ CONSUMIDOR } \\
\hline Confiabilidade no medicamento & Unidades & Constr. direto & Categoria & -1 & 1 \\
\hline Condição de pagamento & Dias & Natural & Quantidade & 0 & 60 \\
\hline Prazo de entrega & Horas & Natural & Quantidade & 1 & 24 \\
\hline Variedade de medicamentos da farmácia & Unidades & Constr. direto & Categoria & -2 & 2 \\
\hline Disponibilidade de estoque matéria-prima & Unidades & Constr. direto & Categoria & 0 & 1 \\
\hline Qualidade no atendimento & Unidades & Constr. direto & Categoria & -2 & 2 \\
\hline Formas de pagamento & Unidades & Constr. direto & Categoria & -1 & 1 \\
\hline Preço do medicamento & Unidades & Constr. direto & Categoria & -1 & 1 \\
\hline Capacidade de produção & Unidades & Constr. direto & Categoria & 0 & 1 \\
\hline \multicolumn{6}{|l|}{ FORNECEDOR } \\
\hline Custo matéria-prima & Reais & Natural & Quantidade & 0,1 & Sem limite \\
\hline Condição de pagamento & Dias & Natural & Quantidade & 1 & Sem limite \\
\hline Qualificação & Unidades & Constr. direto & Categoria & -1 & 1 \\
\hline Validade da matéria-prima & Meses & Natural & Quantidade & 6 & 60 \\
\hline Variedade de matéria-prima & Unidades & Constr. direto & Categoria & -1 & 1 \\
\hline Tamanho da alíquota & Tamanho & Constr. direto & Categoria & 0 & 1 \\
\hline Alíquota & Gramas & Natural & Quantidade & 1 & Sem limite \\
\hline Promoções & Unidades & Constr. direto & Categoria & 0 & 1 \\
\hline Prazo de entrega & Dias & Natural & Quantidade & 1 & 10 \\
\hline Disponibilidade & Unidades & Constr. direto & Categoria & -1 & 1 \\
\hline \multicolumn{6}{|l|}{ ESTOQUE DE MATÉRIA-PRIMA } \\
\hline Giro da matéria-prima & Unidades & Constr. direto & Categoria & -1 & 1 \\
\hline Quantidade da matéria-prima em estoque & Unidades & Constr. direto & Categoria & -1 & 1 \\
\hline Perdas & Percentual & Natural & Quantidade & $10 \%$ & $20 \%$ \\
\hline \multicolumn{6}{|l|}{ MARKETING } \\
\hline Apresentação (produtos, colaboradores) & Unidades & Constr. direto & Categoria & 0 & 1 \\
\hline Propaganda em diversos meios de comunicação & Unidades & Constr. direto & Categoria & -1 & 1 \\
\hline $\begin{array}{l}\text { Melhorias do layout da farmácia Instalações próprias } \\
\text { em geral }\end{array}$ & Unidades & Constr. direto & Categoria & -1 & 1 \\
\hline Visitação médica & Unidades & Constr. direto & Categoria & -1 & 1 \\
\hline Brindes & Unidades & Constr. direto & Categoria & -1 & 1 \\
\hline \multicolumn{6}{|l|}{ CONCORRÊNCIA } \\
\hline Matéria-prima disponível & Unidades & Constr. direto & Categoria & -1 & 1 \\
\hline Preço dos produtos & Unidades & Constr. direto & Categoria & -1 & 1 \\
\hline Condição de pagamento & Dias & Natural & Quantidade & 1 & Sem limite \\
\hline Prazo de entrega & Dias & Natural & Quantidade & 1 & Sem limite \\
\hline Localização & Unidades & Constr. direto & Categoria & -1 & 1 \\
\hline Aspecto físico do produto (qualidade) & Unidades & Constr. direto & Categoria & -1 & 1 \\
\hline \multicolumn{6}{|c|}{ PARCERIAS (médicos, veterinários, dentistas, clínicas de estética, outras farmácias etc.) } \\
\hline Número de parceiros & Unidades & Natural & Quantidade & 0 & Sem limite \\
\hline Divulgação da farmácia & $\begin{array}{l}\text { Unidades } \\
\text { (receitas, indicações) }\end{array}$ & Natural & Quantidade & 0 & Sem limite \\
\hline
\end{tabular}

Tabela 2. Demanda por medicamentos.

\begin{tabular}{cl}
\hline Categoria & \multicolumn{1}{c}{ Descrição } \\
\hline-2 & Muito abaixo: a busca por medicamentos manipulados está muito baixa em relação à média anual. \\
-1 & Abaixo: a busca por medicamentos manipulados está baixa em relação à média anual. \\
0 & Normal: a busca por medicamentos manipulados se mantém na média anual. \\
1 & Alta: a busca por medicamentos manipulados está alta em relação à média anual. \\
2 & Muito Alta: a busca por medicamentos manipulados está muito alta em relação à média anual. \\
\hline
\end{tabular}

Tabela 3. Confiabilidade nos medicamentos da farmácia.

\begin{tabular}{cl}
\hline Categoria & \multicolumn{1}{c}{ Descrição } \\
\hline-1 & $\begin{array}{l}\text { lnsegura: os medicamentos manipulados pela farmácia geram insegurança devido a alterações em suas características } \\
\text { físicas e/ou são extremamente baratos. }\end{array}$ \\
0 & Neutra: os medicamentos manipulados pela farmácia não geram reações positivas ou negativas. \\
1 & Segura: os medicamentos manipulados pela farmácia são totalmente confiáveis, oriundos de fonte segura. \\
\hline
\end{tabular}


Tabela 4. Variedade de medicamentos.

\begin{tabular}{cl}
\hline Categoria & \multicolumn{1}{c}{ Descrição } \\
\hline-2 & $\begin{array}{l}\text { Muito abaixo: não há grande variedade de matérias-primas. } 0 \text { consumidor frequentemente não encontra seu } \\
\text { medicamento na farmácia. }\end{array}$ \\
-1 & $\begin{array}{l}\text { Abaixo: não há variedade de matérias-primas. } 0 \text { consumidor esporadicamente não encontra seu medicamento na } \\
\text { farmácia. }\end{array}$ \\
0 & Normal: há pequena variedade de matérias-primas na farmácia. \\
1 & Alta: há variedade de matérias-primas. O consumidor geralmente encontra seu medicamento na farmácia. \\
2 & Muito alta: há grande variedade de matérias-primas. O consumidor sempre encontra seu medicamento na farmácia. \\
\hline
\end{tabular}

\subsection{Agregação das constantes de escala}

0 uso de modelos aditivos para agregar as decisões do grupo implica que eles têm um efeito compensatório no processo de agregação de todas as preferências dos stakeholders (DAHER; ALMEIDA, 2011). Assim, a obtenção das constantes de escala é uma importante questão no modelo aditivo, visto que não se pode tomar por base apenas o grau de importância dos critérios.

Para facilitar o entendimento da agregação das constantes de escala, apresentam-se as ponderações individuais feitas pelos stakeholders, sendo que os valores das constantes de escala atribuídas aos critérios identificados pela proprietária da farmácia são apresentados na Tabela 5.

A obtenção da avaliação de cada critério é uma função aditiva dos aspectos que o compõem (subcritérios), cujas constantes de escala são bem definidas. Assim, o processo de avaliação consiste em ponderar os subcritérios dentro de cada critério, e os totais de cada critério são novamente ponderados, obtendo-se a avaliação global do processo de precificação dos medicamentos comercializados pela farmácia. A Tabela 6 apresenta os critérios e subcritérios de avaliação da proprietária e as respectivas constantes de escala.

0 mesmo procedimento foi realizado com a responsável técnica. As Tabelas 7 e 8 apresentam, respectivamente, os critérios e subcritérios de avaliação e as respectivas constantes de escala.

Algumas formas de agregação foram analisadas, como a aplicação da média simples entre os valores atribuídos pelos stakeholders a cada atributo. Por exemplo, o atributo receita foi identificado por ambas as stakeholders, porém cada uma o avaliou de acordo com seus valores individuais, chegando à seguinte situação: para a proprietária, o valor para esse atributo seria igual a $13 \mathrm{e}$, para a responsável técnica, seria 4; a média ficaria em 8,5 , porém, dessa forma, o facilitador estaria alterando não apenas o grau de importância do atributo, nesse caso de 13 para 8,5 para a proprietária, e de 4 para 8,5, para a responsável técnica, mas também se perderia a faixa
Tabela 5. Critérios e escalas da proprietária.

\begin{tabular}{lc}
\hline \multicolumn{1}{c}{ Critérios } & Constante de escala (pontos) \\
\hline Receita & 13 \\
Custo variável & 16 \\
Custo fixo & 13 \\
Despesas & 02 \\
Mercado & 07 \\
Consumidor & 13 \\
Fornecedor & 03 \\
Estoque de matéria-prima & 04 \\
Marketing & 09 \\
Concorrência & 10 \\
Parcerias (médicos, veterinários, & 10 \\
dentistas etc....) & \\
\hline
\end{tabular}

de valores considerados no espaço das consequências estabelecido pelas stakeholders.

Outra forma analisada para agregar as constantes de escala foi refazer o processo de aplicação do método VFT após a união dos mapas cognitivos, reelaborando a hierarquia de valores e o estabelecimento das medidas de avaliação dos atributos relacionados ao mapa cognitivo geral além da definição das constantes de escala para a visão geral, interferindo dessa forma nas preferências individuais, visto que no levantamento inicial alguns atributos não tinham sido valorizados por ambas as stakeholders, o que não pareceu ser um procedimento adequado de agregação.

Chegou-se então à soma das constantes de escala de cada atributo, e quando o critério não tinha sido considerado por uma dos stakeholders, receberia valor zero. A Tabela 9 ilustra essa situação. Na primeira coluna encontram-se todos os atributos (critérios) identificados por ambas as stakeholders. Na coluna participação são considerados os valores das constantes de escala da proprietária, identificada pela letra P, e os da responsável técnica, identificada pelas letras RT. Assim, para os atributos pertencentes à estrutura de valores da proprietária, foi transcrito o seu trade-off e, para os atributos não considerados por ela, foi atribuído o valor zero, isso pode ser verificado no critério margem de lucro.

0 mesmo processo foi realizado para a responsável técnica. Para obter-se o valor da constante de escala 
agregada considerando-se o atributo (critério), tomando como exemplo o atributo receita, basta somar os valores 13 , atribuído pela proprietária, e 4, atribuído pela responsável técnica, gerando o valor agregado 17 para a constante de escala geral. Esse procedimento foi realizado para todos os atributos apresentados na Tabela 9.

De acordo com a visão da proprietária, identificada na Tabela 9 pela letra $P$, as opções disponíveis no mercado para formação de preço individualmente não atendem ao modelo de decisão proposto, porque cada opção atende a apenas um conjunto distinto de atributos, por exemplo: pode-se verificar que a opção BC atende integralmente à avaliação de receita, custo fixo, despesas, estoque e marketing, por outro lado, a opção BME atende somente à avaliação do mercado, concorrência e marketing e a opção BCR trabalha somente com a avaliação da valorização do consumidor, concorrência e parceria. Finalmente a opção BMU atende integralmente a receita, custo fixo, custo variável e despesas.

Tabela 6. Subcritérios e escala da proprietária.

\begin{tabular}{|c|c|c|c|}
\hline Critérios & & Subcritérios & $\begin{array}{l}\text { Escala } \\
\text { (pontos) }\end{array}$ \\
\hline Receita & 1 & Quantidade de vendas & 100 \\
\hline \multirow{6}{*}{ Custo variável } & 1 & Custo da matéria-prima & 015 \\
\hline & 2 & Frete & 002 \\
\hline & 3 & Proteção individual & 005 \\
\hline & 4 & Matérias de uso e consumo & 008 \\
\hline & 5 & Taxas e impostos sobre vendas & 020 \\
\hline & 6 & Adequação da RDC & 050 \\
\hline \multirow{6}{*}{ Custo fixo } & 1 & Manutenção corretiva e programada & 020 \\
\hline & 2 & Calibração de equipamentos & 005 \\
\hline & 3 & Controle de qualidade dos processos & 005 \\
\hline & 4 & Seguro patrimonial & 005 \\
\hline & 5 & Recursos humanos & 040 \\
\hline & 6 & $\begin{array}{l}\text { Taxas e impostos (Anvisa, Fubrebom, aluguel, coleta de lixo, } \\
\text { Conselho, anuidades...) }\end{array}$ & 025 \\
\hline \multirow{2}{*}{ Despesas } & 1 & Administrativas & 060 \\
\hline & 2 & Financeiras & 040 \\
\hline \multirow[b]{2}{*}{ Mercado } & 1 & Demanda pelo medicamento & 070 \\
\hline & 2 & $\begin{array}{l}\text { Lançamento de novos medicamentos ou novas formas de } \\
\text { apresentação }\end{array}$ & 030 \\
\hline \multirow{9}{*}{ Consumidor } & 1 & Confiabilidade no medicamento & 005 \\
\hline & 2 & Condição de pagamento & 002 \\
\hline & 3 & Prazo de entrega & 003 \\
\hline & 4 & Variedade de medicamentos & 010 \\
\hline & 5 & Disponibilidade de estoque de matéria-prima & 020 \\
\hline & 6 & Qualidade no atendimento & 008 \\
\hline & 7 & Formas de pagamento & 002 \\
\hline & 8 & Preço do medicamento & 030 \\
\hline & 9 & Capacidade de produção & 020 \\
\hline \multirow{7}{*}{ Fornecedor } & 1 & Custo da matéria-prima & 035 \\
\hline & 2 & Condição de pagamento & 005 \\
\hline & 3 & Qualificação & 005 \\
\hline & 4 & Validade da matéria-prima & 015 \\
\hline & 5 & Variedade de matéria-prima & 010 \\
\hline & 6 & Tamanho da alíquota & 025 \\
\hline & 7 & Promoções & 005 \\
\hline \multirow{3}{*}{ Estoque de matéria-prima } & 1 & Giro da matéria-prima & 040 \\
\hline & 2 & Quantidade em estoque da matéria-prima & 035 \\
\hline & 3 & Perdas & 025 \\
\hline \multirow{3}{*}{ Marketing } & 1 & Apresentação (produtos, colaboradores) & 035 \\
\hline & 2 & Propaganda em diversos meios de comunicação & 035 \\
\hline & 3 & Melhorias do layout da farmácia & 030 \\
\hline \multirow{2}{*}{ Concorrência } & 1 & Matéria-prima disponível & 040 \\
\hline & 2 & Preço dos produtos & 060 \\
\hline \multirow{2}{*}{$\begin{array}{l}\text { Parcerias (médicos, veterinários, dentistas, clínicas de } \\
\text { estética, outras farmácias, etc....) }\end{array}$} & 1 & Número de parceiros & 070 \\
\hline & 2 & Divulgação da farmácia & 030 \\
\hline
\end{tabular}


Na avaliação da responsável técnica, identificada na Tabela 9 pelas letras RT, a opção BC, atende integralmente à avaliação de receita, custo fixo, margem de lucro; por outro lado a opção BME atende integralmente somente à avaliação de receita, margem de lucro, mercado, concorrência e marketing, a opção BCR trabalha com a avaliação da valorização de receita, margem de lucro, mercado, fornecedor, marketing, concorrência; finalmente a opção BMU atende

Tabela 7. Critérios e escalas da responsável técnica.

\begin{tabular}{lc}
\hline \multicolumn{1}{c}{ Critérios } & Constantes de escala (pontos) \\
\hline Receita & 04 \\
Custo variável & 30 \\
Custo fixo & 30 \\
Margem de lucro & 20 \\
Mercado & 05 \\
Fornecedor & 02 \\
Marketing & 05 \\
Concorrência & 04 \\
\hline
\end{tabular}

integralmente a receita, custo fixo, custo variável e margem de lucro. Portanto, as opções disponíveis no mercado para formação de preço não atendem ao modelo de decisão proposto, porque cada opção atende a apenas um conjunto distinto de atributos.

Ambas as stakeholders, coincidentemente, definiram que uma combinação de todos os métodos atuais, considerando e atendendo a todos os subcritérios, seria uma visão mais adequada para o estabelecimento do preço de venda. Assim, uma nova alternativa foi criada com o objetivo de agregar todos os métodos atuais, criando o que foi por elas chamada de alternativa mista.

Dessa maneira é possível verificar e estabelecer um ranking das alternativas mais atraentes de acordo com a opinião de cada participante do processo. Esse ranking das pontuações atribuídas pelas stakeholders é apresentado na Tabela 10. Pode-se notar que há uma grande divergência por parte das atoras do processo, porém ambas concordam que é necessário criar uma nova alternativa que contenha todos os critérios por

Tabela 8. Subcritérios e escalas da responsável técnica.

\begin{tabular}{|c|c|c|c|}
\hline & & Subcritérios & Escala (pontos) \\
\hline Receita & 1 & Quantidade de vendas & 100 \\
\hline \multirow{5}{*}{ Custo variável } & 1 & Custo da matéria-prima & 040 \\
\hline & 2 & Frete & 010 \\
\hline & 3 & Embalagem & 020 \\
\hline & 4 & Custo operacional & 010 \\
\hline & 5 & Impostos (ex.: Simples) & 020 \\
\hline \multirow{6}{*}{ Custo fixo } & 1 & Despesas administrativas & 040 \\
\hline & 2 & Recursos humanos & 030 \\
\hline & 3 & Controle de qualidade & 010 \\
\hline & 4 & Vigilância sanitária & 010 \\
\hline & 5 & Sindicato & 005 \\
\hline & 6 & Conselho Farmacêutico & 005 \\
\hline Margem de lucro & 1 & Margem de lucro & 100 \\
\hline \multirow{5}{*}{ Mercado } & 1 & Público alvo & 050 \\
\hline & 2 & Especialidade médica & 010 \\
\hline & 3 & Forma farmacêutica & 010 \\
\hline & 4 & Matéria-prima por região & 010 \\
\hline & 5 & Convênios & 020 \\
\hline \multirow{6}{*}{ Fornecedor } & 1 & Qualificação & 020 \\
\hline & 2 & Prazo de entrega & 020 \\
\hline & 3 & Disponibilidade & 020 \\
\hline & 4 & Variedade & 010 \\
\hline & 5 & Alíquota & 020 \\
\hline & 6 & Condição de pagamento & 010 \\
\hline \multirow{4}{*}{ Marketing } & 1 & Propaganda em meios de comunicação & 040 \\
\hline & 2 & Visitação médica & 030 \\
\hline & 3 & Instalações próprias em geral & 020 \\
\hline & 4 & Brindes & 010 \\
\hline \multirow{5}{*}{ Concorrência } & 1 & Preço & 030 \\
\hline & 2 & Condição de pagamento & 010 \\
\hline & 3 & Prazo de entrega & 020 \\
\hline & 4 & Localização & 020 \\
\hline & 5 & Aspecto físico do produto (qualidade) & 020 \\
\hline
\end{tabular}


Tabela 9. Avaliação das alternativas.

\begin{tabular}{|c|c|c|c|c|c|c|c|c|c|c|c|c|}
\hline \multirow{2}{*}{ Critérios } & \multicolumn{2}{|c|}{ Participação } & \multicolumn{2}{|c|}{$\mathrm{BC}$} & \multicolumn{2}{|c|}{ BME } & \multicolumn{2}{|c|}{ BCR } & \multicolumn{2}{|c|}{ BMU } & \multicolumn{2}{|c|}{ Mista } \\
\hline & $\mathrm{P}$ & RT & $\mathrm{P}$ & RT & $\mathrm{P}$ & RT & $\mathrm{P}$ & RT & $\mathrm{P}$ & RT & $\mathrm{P}$ & RT \\
\hline Receita & 13 & 04 & 13,00 & 4,00 & 0,00 & 4,00 & 0,00 & 4,00 & 13,00 & 4,00 & 13,00 & 4,00 \\
\hline Custo fixo & 13 & 30 & 13,00 & 30,00 & 0,00 & 9,00 & 0,00 & 21,00 & 13,00 & 30,00 & 13,00 & 30,00 \\
\hline Custo variável & 16 & 30 & 15,84 & 25,20 & 0,00 & 24,00 & 0,00 & 28,50 & 16,00 & 30,00 & 16,00 & 30,00 \\
\hline Mercado & 07 & 05 & 0,00 & 0,00 & 7,00 & 5,00 & 2,10 & 5,00 & 0,00 & 1,00 & 7,00 & 5,00 \\
\hline Fornecedor & 03 & 02 & 1,20 & 0,00 & 0,00 & 1,00 & 1,50 & 2,00 & 1,05 & 0,00 & 3,00 & 2,00 \\
\hline Marketing & 09 & 05 & 9,00 & 3,50 & 9,00 & 5,00 & 2,70 & 5,00 & 0,00 & 3,50 & 9,00 & 5,00 \\
\hline Concorrência & 10 & 04 & 0,00 & 0,00 & 10,00 & 4,00 & 10,00 & 4,00 & 0,00 & 0,00 & 10,00 & 4,00 \\
\hline Margem de lucro & 00 & 20 & 0,00 & 20,00 & 0,00 & 20,00 & 0,00 & 20,00 & 0,00 & 20,00 & 0,00 & 20,00 \\
\hline Consumidor & 13 & 00 & 3,90 & 0,00 & 10,40 & 0,00 & 13,00 & 0,00 & 0,00 & 0,00 & 13,00 & 0,00 \\
\hline Despesas & 02 & 00 & 2,00 & 0,00 & 0,00 & 0,00 & 0,00 & 0,00 & 2,00 & 0,00 & 2,00 & 0,00 \\
\hline Estoque & 04 & 00 & 4,00 & 0,00 & 0,00 & 0,00 & 0,00 & 0,00 & 0,00 & 0,00 & 4,00 & 0,00 \\
\hline Parcerias & 10 & 00 & 0,00 & 0,00 & 0,00 & 0,00 & 10,00 & 0,00 & 0,00 & 0,00 & 10,00 & 0,00 \\
\hline TOTAL & 100 & 100 & 61,94 & 82,7 & 36,4 & 72,0 & 39,3 & 89,5 & 45,05 & 88,5 & 100,00 & 100,00 \\
\hline Total geral & \multicolumn{2}{|c|}{200,00} & \multicolumn{2}{|c|}{144,64} & \multicolumn{2}{|c|}{108,40} & \multicolumn{2}{|c|}{128,80} & \multicolumn{2}{|c|}{133,85} & \multicolumn{2}{|c|}{200,00} \\
\hline
\end{tabular}

Tabela 10. Ranking das alternativas.

\begin{tabular}{lccc}
\hline Alternativa & $\begin{array}{c}\text { Visão } \\
\text { proprietária }\end{array}$ & $\begin{array}{c}\text { Visão da } \\
\text { responsável } \\
\text { técnica }\end{array}$ & $\begin{array}{c}\text { Visão } \\
\text { agregada }\end{array}$ \\
\hline Mista & 100,00 & 100,00 & 200,00 \\
BC & 061,94 & 082,70 & 144,64 \\
BMU & 045,05 & 088,50 & 133,85 \\
BCR & 039,30 & 089,50 & 128,80 \\
BME & 036,40 & 072,00 & 108,40 \\
\hline
\end{tabular}

elas considerados importantes no estabelecimento do preço de venda.

Pode-se concluir que não é suficiente o preço de venda cobrir os custos e despesas da empresa, muito menos cobrir ofertas da concorrência, ou ainda disponibilizar todos os serviços e demais preocupações com o mercado. A proposta deve atender a todas essas visões, criando uma alternativa mista para atender a todos os aspectos pertinentes na busca de um preço de venda mais competitivo.

\subsection{Análise de sensibilidade}

Por fim, a última etapa da abordagem prevê a realização da análise de sensibilidade, cujo objetivo é explorar como as mudanças no modelo podem influenciar a recomendação de decisão. Se uma pequena mudança em um ou vários aspectos da árvore de decisão faz com que o valor seja recomendado para a mudança, a decisão é dita ser sensivel a essas mudanças. Reconhecer os aspectos em que a decisão é sensivel permite que o decisor se concentre, ou, eventualmente, reconsidere as questões, o que pode causar alterações na decisão.

Além disso, essa análise de sensibilidade é usada para examinar se o modelo é robusto a alterações nos seus parâmetros. Essa análise permite que se saiba se uma pequena alteração, por exemplo, da constante de escala de um critério vai causar uma grande variação na avaliação das ações potenciais. Se uma pequena variação de algum parâmetro causar grandes variações na avaliação final das ações, o modelo não é robusto e os resultados obtidos devem ser encarados com cuidado, sendo necessária, muitas vezes, uma reavaliação dos parâmetros utilizados. A análise consiste, usualmente, em mudar os valores dos parâmetros e observar o que acontece no resultado final.

Para avaliar o grau de sensibilidade dos resultados apresentados neste estudo foi realizada a simulação de diferentes cenários, essa análise visa garantir e corroborar os resultados sugeridos. Essas simulações foram feitas basicamente com a alteração das constantes de escala dos atributos mais significativos de todo o processo de seleção do método que geraria um preço de venda mais competitivo. Essa alteração permite verificar o quão sensível é o atual ranking das alternativas em relação às mudanças.

Várias simulações foram realizadas e a análise de sensibilidade confirmou que a alternativa mista é considerada a melhor por atender a todos os atributos do modelo, portanto se algum fator sofrer alteração, essa alternativa permanece sendo a mais adequada.

\section{Considerações finais}

Este trabalho propôs uma abordagem para estruturação de problema em grupo baseado no método VFT associado com mapeamento cognitivo, a fim de agregar os diferentes pontos de vista dos stakeholders envolvidos no processo decisório. Esta abordagem foi aplicada no processo de definição do 
preço de venda dos medicamentos produzidos por uma farmácia de manipulação, para identificar os fatores que corroboram com a prática de um preço de venda mais competitivo. A decisão final considerou todos os interesses, percepções e preferências dos stakeholders, a partir da agregação dos pontos de vista individuais, gerando um modelo consolidado e único, possibilitando à farmácia de manipulação condições de concorrer com inúmeros desafios advindos do nicho de mercado ao qual pertence.

É importante destacar que embora tenha sido aplicada a abordagem de agregação para poucos decisores, o processo de agregação das opiniões dos stakeholders pode ser ampliado para o número de participantes que for necessário, o que certamente contribuirá com uma melhor percepção do problema, possibilitando encontrar uma solução mais adequada para os critérios estabelecidos.

A combinação do método VFT com o mapeamento cognitivo do método SODA contribuiu enormemente na obtenção dos valores dos stakeholders. É possível afirmar que o mapeamento cognitivo facilitou a identificação do objetivo estratégico fundamental e dos objetivos meios propostos pelo VFT, no qual as diferentes percepções do problema foram combinadas, registradas e validadas, valorizando os interesses individuais dos atores participantes do processo de decisão.

Através da utilização de mapas cognitivos do método SODA foi gerada uma grande quantidade de informações sobre a situação problema, fazendo com que houvesse um aumento significativo do conhecimento dos decisores em relação a ela. Essa característica dos mapas foi muito útil na construção da hierarquia de valores, uma vez que a partir do mapa foi possível determinar quais eram os objetivos dos atores e as características das ações que os decisores julgaram importantes.

0 facilitador pôde, através da união de conjuntos, reunir os mapas cognitivos individuais para obter o mapa agregado e estabelecer um procedimento sistemático para obtenção de diversas percepções sem a necessidade de estabelecer um processo de negociação, evitando dessa forma possíveis conflitos em função de divergências advindas de preferências e interesses particulares.

Após a identificação das medidas de avaliação da estrutura hierárquica, extraídas do mapa cognitivo agregado, as alternativas determinadas pelas stakeholders para a definição do preço de venda dos medicamentos foram o método baseado nos custos, no mercado, no mark-up e na concorrência. Tais métodos foram submetidos e analisados de acordo com a estrutura de atributos obtidos a partir da abordagem proposta. Cada stakeholder avaliou e em seguida o facilitador reuniu as avaliações, atribuindo zero para o critério inexistente dentro da estrutura de medidas de cada ator e somando as constantes identificadas de cada decisor, chegando a um ranking das alternativas.

Para identificar se cada opção atendia aos atributos que compõem a estrutura hierárquica de valores dos skateholders, cada participante decidiu se o atributo poderia ou não ser analisado para a opção em questão. ldentificou-se que nenhuma alternativa disponível no mercado atende a todos os atributos da estrutura hierárquica de valores das stakeholders. Dessa forma, foi criada uma nova alternativa denominada mista, a qual reuniu todos os atributos, chegando aos valores finais de cada alternativa, dentro de cada critério.

Conclui-se que é possivel realizar a estruturação de um problema específico através da utilização do VFT por diferentes stakeholders sem necessidade de estabelecer um processo de negociação entre 0 grupo, reduzindo possíveis conflitos que pudessem ocorrer, utilizando para tanto a união dos pontos de vista de cada ator e gerando um modelo único e rico em informações por agregar diferentes percepções dos atores. Admite-se, no entanto, que após a apresentação da solução pelo facilitador poderão ocorrer divergências, sendo necessário, então, estabelecer um processo de negociação com o grupo de stakeholders para dirimir as divergências ocorridas no processo de validação da solução apresentada.

\section{Referências}

AGÊNCIA NACIONAL DE VIGILÂNCIA SANITÁRIA - ANVISA. Resolução RDC no 33, de 19 de abril de 2000. Aprova o regulamento técnico sobre Boas Práticas de Manipulação de Medicamentos em farmácias. Diário Oficial da República Federativa do Brasil, Basília, DF, abr. 2000.

ALENCAR, L. H.; ALMEIDA, A. T. A model for selecting project team members using multicriteria group decision making. Pesquisa Operacional, v. 30, 2010a.

ALENCAR, L. H.; ALMEIDA, A. T. Multicriteria Decision Group Model for Suppliers Selection. Pesquisa Operacional, v. $28,2010 b$.

ALENCAR, L. H.; MORAIS, D. C.; ALMEIDA, A. T. A multicriteria group decision model aggregating the preferences of decision-makers based on ELECTRE methods. Pesquisa Operacional, v. 30, n. 3, p. 687-702, 2010. http://dx.doi. org/10.1590/S0101-74382010000300010

ALENCAR, L. H.; MOTA, C. M. M.; ALENCAR, M. H. The problem of disposing of plaster waster of building sites: problem structuring based on value focus thinking methodology. Waste Management, v. 31, n. 12, p. 25122521, 2011. PMid:21816597. http://dx.doi.org/10.1016/j. wasman.2011.06.015

ALMEIDA, A. T. O conhecimento e o uso de métodos multicritério de apoio à decisão. 2. ed. Recife: Editora Universitária UFPE, 2011. 
ASSOCIAÇÃO NACIONAL DE FARMACÊUTICOS MAGISTRAIS - ANFARMAG. Disponivel em: <http://www. anfarmag.org.br/home.php>. Acesso em: 12 jul. 2011.

BOSE, U.; DAVEY, A. M.; OLSON, D. L. Multi-attribute Utility Methods in Group Decision Making: Past Applications and Potential for Inclusion in GDSS. OMEGA - The International Journal of Management Science, v. 25, n. 6, p. 691-706, 1997.

CHECKLAND, P. Soft Systems Methodology. In: ROSENHEAD, J.; MINGERS, J. (Eds.). Rational Analysis for a Problematic World Revisited. 2nd ed. Chichester: Jonh Wiley \& Sons Ltd, 2004.

DAHER, S. F. D.; ALMEIDA, A. T. The Use of Ranking Veto Concept to Mitigate the Compensatory Effects of Additive Aggregation in Group Decisions on a Water Utility Automation Investment. Group Decision and Negotiation, v. 21, n. 2, p. 185-204, 2011. http://dx.doi. org/10. 1007/s10726-011-92

DUTRA, D. J. S.; HATAKEYAMA, K. Preço de venda: a utilização da margem sobre o preço de venda. In: ENCONTRO ESTADUAL DE ENGENHARIA DA PRODUÇÃO, 1.; SIMPÓSIO DE GESTÃO INDUSTRIAL, 1., 2005, Ponta Grossa. Anais... Ponta Grossa: UTFPR, 2005.

EDEN, C.; ACKERMANN, F. Cognitive mapping expert views for policy analysis in the public sector. European Journal of Operational Research, v. 152, p. 615-630, 2004. http://dx.doi.org/10.1016/S0377-2217(03)00061-4

FRIEND, J. The strategic choice approach. In: ROSENHEAD, J.; MINGERS, J. (Eds. ). Rational Analysis for a Problematic World Revisited. 2nd ed. Chichester: Jonh Wiley \& Sons Ltd, 2004.

GOMES, L. F.; GOMES, C. F. S.; ALMEIDA, A. T. Tomada de Decisão Gerencial: um enfoque multicritério. 3. ed. São Paulo: Atlas, 2009.

KEENEY, R. L. Value-Focused Thinking: A Path to Creative Decision Making. Cambridge: Harvard University Press, 1992.

KEENEY, R. L. Value-Focused Thinking: Identifying decision opportunities and creating alternatives. European Journal of Operational Research, v. 92, n. 3, p. 537-549, 1996. http://dx.doi.org/10.1016/0377-2217(96)00004-5

KIRKW00D, C. W. Strategic Decision Making: Multi Objective Decision Analysis with Spreadsheets. Belmont: Wadsworth Publishing Company, 1997.

MORAIS, D. C.; ALMEIDA, A. T. Water network rehabilitation: A group decision-making approach. Water $S A$, v. 36, n. 4, p. 487-493, 2010. http://dx.doi.org/10.4314/wsa. v36i4.58425

MORAIS, D. C.; ALMEIDA, A. T. Group decision making on water resources based on analysis of individual rankings. OMEGA - The International Journal of Management Science, vol. 40, p. 42-52, 2012.

SANTOS, J. J. Fundamentos de Custos para a Formação do Preço e do Lucro. 5. ed. São Paulo: Atlas, 2005.

SARTORI, E. Gestão de preços. São Paulo: Atlas, 2004.

WARFIELD, J. N. A science of Generic Design: Managing complexity through systems design. 2nd ed. lowa State University Press, 1994.

WINTER, M. Problem structuring in Project management: an application of soft systems methodology (SSM). Journal of the Operational Research Society, v. 57, p. 802-812, 2006. http://dx.doi.org/10.1057/palgrave. jors.26020505

\section{Agradecimentos}

Este trabalho foi desenvolvido com suporte parcial da Capes e do CNPq. Os autores agradecem a participação de todos os stakeholders, que se disponibilizaram para a coleta de normas, regras e pontos de vista na identificação da importância da formação adequada do preço de venda. Os autores agradecem também as valiosas sugestões feitas pelos revisores anônimos que contribuíram para a melhoria deste trabalho.

\title{
Aggregation of stakeholder viewpoints using the value-focused thinking methodology in association with cognitive maps
}

\begin{abstract}
This study proposes a new approach for aggregating the opinions of different stakeholders based on value-focused thinking combined with cognitive mapping. This approach was applied to determine selling prices, focusing on the particular case of a compounding pharmacy in southern Brazil. This method provides a better understanding of the problem with respect to the members involved. This paper also identifies the implications of working with individual stakeholders, generating different models and combining the viewpoints to obtain a unique result in the process of product pricing.
\end{abstract}

\section{Keywords}

Establishment of sales price. Decision making. Value-focused thinking. Cognitive map. 